men were at a disadvantage, for they could only work in their spare time, and their means were slender. Thomas had managed during twelve years service as a clerk to save $£ 800$. This money enabled them to take out two patents-No. 4422 in 1877 and No. 289 in 1878.

Thus far the work had demonstrated the possibility of their process but no more, and they then entered. upon a period of difficulty and shortage of money. Mr. Martin, the general manager of the Blaenavon Steel Company in South Wales, came to their assistance, and on March 6, 1878, another patent, No. 908, was taken out. After this, rapid progress was made, and at the autumn meeting of the Iron and Steel Institute, held that year in Paris, they presented a paper entitled "On the Elimination of Phosphorus in the Bessemer Converter". So little was its importance realised that it was not even read, but was adjourned until the meeting in 1879 , when it was read by Thomas and published in the Journal of the Institute.

Actually this delay was a fortunate occurrence. Among the members attending the meeting was $\mathrm{E}$. Windsor Richards, of Bolckow, Vaughan and Co., Ltd. He made the acquaintance of Thomas, and was so impressed by the importance of the discovery and the personality of the inventor that he determined there and then to urge his directors to give the process a trial. This consent was forthcoming. Windsor Richards and J. E. Stead, consultant to the company, then undertook, in collaboration with Thomas and Gilchrist, the practical development of the process. The difficulties which had to be overcome are well described by Stead in his presidential address to the Iron and Steel Institute in 1920. Certain conditions had to be satisfied. It was necessary to line the converter with a basic material, not merely of the correct composition but also of the requisite texture and stability so that its adhesion to the converter walls during the 'blow' was maintained. It was also necessary to form a rich basic slag at an early stage of the process. Finally, it was found that while the carbon, silicon and manganese in the iron were removed at an early stage of the blow, the phosphorus was not sensibly diminished until later. This necessitated the so-called 'after blow', during which about 80 per cent of the phosphorus that is removed is eliminated.

The first successful charge was blown on April 4, 1879 , using an experimental 30-cwt. converter which had been erected for the purpose. A brochure issued by Bolckow, Vaughan and Co. in 1929, the fiftieth anniversary of this event, contains the details of the actual blow and the elimination of the various impurities from the iron. Accordingly, when Thomas read the paper at the spring meeting of the Iron and Steel Institute, practical success had been achieved. In this way the basic Bessemer process was established, and for many years proved to be one of the main processes for producing cheap steel on a large scale. Provided an iron contained the requisite amount of phosphorus, it could be treated by this process. In this way the great phosphoric iron ore deposits were rendered amenable to treatment.
In one respect, the basic Bessemer process is more important than the acid Bessemer process. In the latter the ferruginous slag is a waste product. In the former, Thomas and Gilchrist had discovered the chemical conditions necessary to fix in a stable form the phosphoric acid produced by the oxidation of the phosphorus in the pig iron. A highly basic phosphate of calcium is produced which is similar in composition to the mineral phosphates of North Africa. It is eminently suitable as a plant food, and a demand for basic slag as a fertiliser grew rapidly. Strictly speaking, there is no by-product in the basic Bessemer process, for both steel and slag find a market. Both the steel industry and agriculture are thus greatly indebted to the work of Thomas and Gilchrist.

In Great Britain, the basic Bessemer process has been, to a great extent, superseded by the basic openhearth process, which enables much larger charges to be worked; it does not require the same limits of composition of the iron, and is amenable to better control. But it has never been completely superseded, and to-day there is indeed a tendency to return to it for certain purposes. A large steel plant which is operating in the Midlands at the present time is working this process.

Gilchrist was the son of Mr. Alexander Gilchrist, a barrister. He was born at Lyme Regis on September 27, 1851. He attended Felsted School and the Royal School of Mines, where he became Murchison medallist. He was elected a fellow of the Royal Society in 1891. He was a vice-president of the Iron and Steel Institute, a member of the Society of Chemical Industry, and a fellow of the Royal Society of Arts. $\mathrm{He}$ was also a Chevalier of the Legion of Honour. He married in 1887 Nora, daughter of Captain Fitzmaurice, R.N., and had a son and a daughter. He has survived his collaborator Thomas for more than fifty years.

H. C. H. C.

\section{Dr. Albert A. Gray}

Dr. Albert A. Gray, who died in London on January 6, at the age of sixty-seven years, spent his active professional life in Glasgow, where he held the post of lecturer in otology in the University and of aural surgeon to the Infirmary.

Dr. Gray was known at home and abroad as the author of "The Labyrinth of Animals" (2 vols.). This magnificent work demonstrated the naked eye structure of the internal ear of vertebrate animals in a now way. He improved the technique of clarifying specimens to a degree which permitted him to expose in all its detail the internal ear within the transparent temporal bone of all vertebrate animals. In this way he was able to add many new facts to the comparative anatomy of the ear. He sought to found the practice of the ear surgeon on a scientific basis, applying himself in particular to that prevalent cause of deafness known as otosclerosis.

Many marks of recognition were received by Dr. Gray from his professional brethren; he was elected president of the otological section of the Royal Society of Medicine and of the corresponding section of the British Medical Association. 